\title{
Energy balance in depleted ambulatory patients with chronic obstructive pulmonary disease: the effect of physical activity and oral nutritional supplementation
}

\author{
Annelies H. C. Goris ${ }^{1}$, Marja A. P. Vermeeren ${ }^{2}$, Emiel F. M. Wouters ${ }^{3}$, \\ Annemie M. W. J. Schols ${ }^{3}$ and Klaas R. Westerterp ${ }^{1}$ \\ ${ }^{1}$ Department of Human Biology, Maastricht University, Maastricht, The Netherlands \\ ${ }^{2}$ Department of Dietetics and Respiratory Medicine, University Hospital Maastricht, \\ PO Box 5800, 6202 AZ MAASTRICHT, The Netherlands \\ ${ }^{3}$ Department of Respiratory Medicine, Maastricht University, Maastricht, The Netherlands
}

(Received 10 July 2002 - Revised 6 December 2002 - Accepted 28 December 2002)

\begin{abstract}
Patients with chronic obstructive pulmonary disease (COPD) often suffer from weight loss. The aim of the present study was to gain insight into the energy balance of depleted ambulatory COPD patients, in relation to their habitual level of physical activity and consumption of oral nutritional supplements. Clinically stable and weight-stable patients ( $n$ 20; BMI 19.8 \pm SD $2 \cdot 0 \mathrm{~kg} / \mathrm{m}^{2}$ ) were studied 1 and 3 months after rehabilitation or recovery in the clinic and were at random assigned to a control or intervention group with regard to nutritional supplementation. Energy intake was measured with a $7 \mathrm{~d}$ food record. Energy expenditure was estimated from a simultaneous $7 \mathrm{~d}$ assessment of physical activity with a tri-axial accelerometer for movement registration in combination with measured BMR. Body mass was measured at several time points. The body mass remained stable in both groups after 1 or 3 months and mean energy balances were comparable for both groups. The mean body-mass change between month 1 and 3 was negatively related to the mean physical activity level $(r-0.49 ; P=0.03)$. Weight change over the 3 months was negatively associated with the physical activity level. These results suggest that knowledge about the individual physical activity level is necessary for the estimation of the energy need of the COPD patient.
\end{abstract}

Energy balance: Depleted ambulatory chronic obstructive pulmonary disease patients: Physical activity level

Patients with chronic obstructive pulmonary disease (COPD) often suffer from weight loss due to an inadequate dietary intake combined with an increased energy expenditure (EE) (Schols et al. 1991). Nutritional depletion in COPD patients influences functional status and healthrelated quality of life (Wilson et al. 1989; Schols et al. 1998; Creutzberg et al. 2003; Mostert et al. 2000). Insight into factors related to the energy balance of depleted COPD patients at home helps to optimise the nutritional status of patients at home.

Nutritional therapy in a rehabilitation setting improves the physical condition of depleted COPD patients, especially when it is combined with exercise or another anabolic stimulus such as anabolic steroids (Schols et al. 1995; Creutzberg et al. 2003). The success of nutritional therapy in ambulatory depleted COPD patients varies and probably depends partly on compliance and appropriate incorporation of the supplements, as there is less control on the food intake of the patients than in a clinical situation (Lewis et al. 1987; Efthimou et al. 1988).

An increase in energy intake by supplementation does not necessarily imply a positive energy balance. The energy balance of ambulatory depleted COPD patients is also a function of the energy requirement of the patients. Physical activity, as the main determinant of variation in energy requirement, may play an important role. In particular,

Abbreviations: COPD, chronic obstructive pulmonary disease; EE, energy expenditure.

* Corresponding author: Dr Marja Vermeeren, fax +31 433875159, email vermeeren.marja@zonnet.nl 
previous studies by our group have demonstrated an increased energy requirement for physical activity in severe COPD patients (Baarends et al. 1997).

The aim of the present study was to gain insight into the energy balance of ambulatory depleted COPD patients in relation to their habitual physical activity. A secondary aim of the study was to look at the effect of the consumption of nutritional supplements on energy balance. EE and energy intake were estimated at 1 and 3 months after discharge from the clinic (after recovery of an exacerbation or after rehabilitation in a pulmonary rehabilitation centre). Reported food intake was controlled for misreporting or a change in diet while food recording (Goris \& Westerterp, 1999; Goris et al. 2000).

\section{Subjects and methods}

\section{Protocol}

Depleted COPD patients ( $n$ 20) were studied 1 and 3 months after discharge from the university hospital in Maastricht or from the pulmonary rehabilitation centre in Horn, The Netherlands. At discharge all patients were in a clinically and weight-stable condition. The patients were then at random assigned (with a randomisation table) to the intervention group or to the control group. The intervention group received $3 \times 125 \mathrm{ml}$ Respifor ${ }^{\circledR}$ (sip-feed, Nutricia, The Netherlands) daily. The nutritional supplement of $375 \mathrm{ml}$ provided $2.38 \mathrm{MJ} / \mathrm{d}$, with $20 \%$ energy as protein, $20 \%$ energy as fat and $60 \%$ energy as carbohydrate. Patients were advised to take the supplements in the morning, the afternoon and in the evening respectively. All patients received nutritional advices from a dietitian on how to increase their energy intake. Patients from the hospital and rehabilitation centre were equally distributed between the intervention group and control group. Food intake, EE and water loss (to check for misrecording, see also p. 729) were measured together over a 1-week period. Measurements of body mass gave insight into whether subjects were in energy balance while food recording. None of the patients participated in an outpatient or home-based pulmonary rehabilitation programme.
Subjects

Inclusion criteria were a BMI $\leq 22 \mathrm{~kg} / \mathrm{m}^{2}$ or a BMI $\leq 25 \mathrm{~kg} / \mathrm{m}^{2}$ in combination with recent weight loss ( $>5 \%$ of usual body mass). Exclusion criteria were severe cardiovascular disease, gastrointestinal abnormalities or endocrine disease, malignancies or dementia. Patients were informed about the aim and procedures of the study and they gave written consent. The medical ethics committee of the university and the hospital approved the protocol. The characteristics of the subjects at discharge are described in Table 1. Patients had a moderate to severe airflow obstruction in combination with normal blood gases.

\section{Body mass}

Body-mass measurements were performed at month 1 and month 3 after discharge and were measured three times, with $7 \mathrm{~d}$ intervals, 1 week before the start of the recording week, at the start and at the end of the recording week. Thus, possible weight changes due to a change of diet while food recording can be compared with normal body-mass fluctuations. Patients were weighed in indoor clothing and without shoes, in the morning before any drink or beverage consumption and after voiding, on a digital balance accurate to $\pm 0.1 \mathrm{~kg}$ (Seca, Almere, The Netherlands). The balances used in the hospital and in the rehabilitation centre were calibrated.

\section{Food and water intake}

A $7 \mathrm{~d}$ food record was used to measure total food and water intake (at month 1 and month 3 together with the measurement of EE and water loss). Subjects received instructions from a dietitian on how to fill in the food record. The food records were converted into intakes of total energy, macronutrients and water with a computer program based on food tables (Becel Nutrition Program; Nederlandse Unilever Bedrijven B.V., Rotterdam, The Netherlands). The amount of metabolic water was calculated by multiplying EE by the percentages of energy from protein, fat, and carbohydrate from the $7 \mathrm{~d}$ food record. Oxidation of protein

Table 1. Characteristics of patients with chronic obstructive pulmonary disease at discharge

(Mean values and standard deviations)

\begin{tabular}{|c|c|c|c|c|c|c|}
\hline & \multicolumn{2}{|c|}{ Intervention group* } & \multicolumn{2}{|c|}{ Control group* } & \multicolumn{2}{|c|}{ Total } \\
\hline & Mean & SD & Mean & SD & Mean & SD \\
\hline Sex: Men (n) & \multicolumn{2}{|c|}{6} & \multicolumn{2}{|c|}{5} & \multicolumn{2}{|c|}{11} \\
\hline Women $(n)$ & \multicolumn{2}{|c|}{5} & \multicolumn{2}{|c|}{4} & \multicolumn{2}{|c|}{9} \\
\hline Age (years) & 61 & 12 & 62 & 10 & 62 & 11 \\
\hline BMI $\left(\mathrm{kg} / \mathrm{m}^{2}\right)$ & $19 \cdot 6$ & $2 \cdot 4$ & $20 \cdot 0$ & 1.5 & $19 \cdot 8$ & $2 \cdot 0$ \\
\hline $\mathrm{FEV}_{1}(\%$ predicted $)$ & 40 & 13 & 41 & 19 & 40 & 16 \\
\hline IVC (\% predicted) & 94 & 12 & 83 & 18 & 89 & 16 \\
\hline $\mathrm{PaO}_{2}(\mathrm{kPa})$ & 9.4 & 1.4 & 9.5 & $1 \cdot 1$ & 9.5 & 1.3 \\
\hline $\mathrm{PaCO}_{2}(\mathrm{kPa})$ & $5 \cdot 5$ & 0.9 & $5 \cdot 8$ & 0.7 & $5 \cdot 6$ & 0.8 \\
\hline
\end{tabular}

$\mathrm{FEV}_{1}$, forced expiratory volume in $1 \mathrm{~s}$; IVC, inspiratory vital capacity; $\mathrm{PaO}_{2}$, arterial $\mathrm{O}_{2}$ tension; $\mathrm{PaCO}_{2}$, arterial $\mathrm{CO}_{2}$ tension.

${ }^{*}$ No baseline differences were found between the intervention and control group $(P>0.05)$. 
yields $0.41 \mathrm{ml}$ water $/ \mathrm{g}$, fat yields $1.07 \mathrm{ml}$ water $/ \mathrm{g}$ and carbohydrate yields $0.60 \mathrm{ml}$ water/g (Fjeld et al. 1988).

\section{Energy expenditure}

Energy expenditure was estimated from measured BMR and physical activity assessed with a tri-axial accelerometer for movement registration. BMR was measured at the start of the recording week after an overnight fast, while lying for $30 \mathrm{~min}$ in a supine position, with a ventilated hood system (Oxycon- $\beta$; Mijnhardt, Bunnik, The Netherlands).

Physical activity was estimated with a tri-axial accelerometer for movement registration (Tracmor) during the recording week. The Tracmor is a small device $(70 \times 20 \times 8 \mathrm{~mm} ; 30 \mathrm{~g})$, which measures accelerations in the anteroposterior, mediolateral and vertical directions of the trunk. Subjects wore the Tracmor during waking hours for $7 \mathrm{~d}$ in a belt at the back of the waist. The Tracmor has been validated against doubly labelled water, in a group of men and women between 55 and 74 years, which gave the following formula using Tracmor counts and BMR for the calculation of total EE:

$$
\begin{aligned}
\mathrm{EE}(\mathrm{MJ} / \mathrm{d})= & -2.289+(1.777 \times \mathrm{BMR}(\mathrm{MJ} / \mathrm{d})) \\
& +(0.063 \times \text { counts } / \mathrm{min}) .
\end{aligned}
$$

The regression analysis for this equation is $r^{2} 0.82$; $P<0.0001$ with twenty-six healthy elderly subjects (Goris et al. 2000). The physical activity level was calculated by expressing $\mathrm{EE}$ as a multiple of BMR (physical activity level $=\mathrm{EE} / \mathrm{BMR}$ ).

\section{Water loss}

Water loss was measured with the ${ }^{2} \mathrm{H}$ elimination method. The evening before the start of the recording week subjects drank a weighed dose of ${ }^{2} \mathrm{H}$ dilution, $70 \mathrm{~g}$ water with an enrichment of 5 atom $\%$ excess ${ }^{2} \mathrm{H}$, after voiding (background sample). Subjects collected urine samples in the morning and evening of day 1 , at the start of the recording week, the evening of day 7 and the morning of day 8. Water loss was calculated from ${ }^{2} \mathrm{H}$ elimination with the equation of Fjeld et al. (1988), as described previously (Westerterp et al. 1992).

\section{Statistics}

Mean and standard deviations were calculated. Differences between groups were tested with the Wilcoxon rank-sum test and differences between measurements within groups were tested with paired sign tests. A paired $t$ test was used to test differences between the two periods within the total group. Correlation coefficients were calculated to describe relationships between parameters.

Body-mass changes and mean physical activity levels of month 1 and 3 were calculated for nineteen subjects, because one subject went to the rehabilitation centre at month 2 .

The calculation of the power of the study was not based on expected changes in body mass between the control and the supplemented group, as the main focus of the present study was to elucidate the influence of physical activity on energy balance. Significance was set at $P<0 \cdot 05$.

\section{Results}

The body-mass change between discharge and month 1 was -0.1 (SD 1.0) (range -1.6 to 2.3 ) $\mathrm{kg}$ and 0.3 (SD 2.3) (range $-2 \cdot 3$ to $5 \cdot 1$ ) $\mathrm{kg}$ for the intervention group and for the control group, respectively (Wilcoxon rank-sum test, $P=0 \cdot 6)$. Between month 1 and month 3 the body-mass change was 0.3 (SD 1.4) (range -1.8 to 2.9 ) $\mathrm{kg}$ and -0.0 (SD 2.4) (range -4.4 to 3.4 ) $\mathrm{kg}$ for the intervention group and for the control group, respectively (Wilcoxon rank-sum test, $P=0 \cdot 9$ ).

Results for energy intake and expenditure at month 1 and month 3 are presented in Table 2. Energy intake was not significantly different from EE, neither for the intervention group, nor for the control group. There was no statistical significant difference in energy balance between the two groups (month 1 Wilcoxon rank-sum test, $P=0 \cdot 50$; month 3 Wilcoxon rank-sum test, $P=0 \cdot 49)$. The intervention group had a positive energy balance of 0.8 (SD 2.3) $\mathrm{MJ} / \mathrm{d}$ and the control group had a negative energy balance of -0.7 (SD 2.5) $\mathrm{MJ} / \mathrm{d}$ in the first month. In the third month the intervention group had a small negative energy balance of $-0 \cdot 1$ (SD 2.2) $\mathrm{MJ} / \mathrm{d}$ and the control group had a positive energy balance of 0.6 (SD 1.9) $\mathrm{MJ} / \mathrm{d}$.

The body-mass changes over both recording weeks were not different from the body-mass changes over the non-recording weeks (see Table 3 ). The patients did not change their diet while food recording, nor did they incorrectly record their food intake; there was also no difference in reported water intake and measured water loss (see Table 3).

The differences in body-mass change over time between patients could not be explained by the reported energy intakes $(P=0 \cdot 32)$. The mean body-mass change from month 1 to month 3 was negatively correlated with the mean physical activity level (Fig. 1; correlation $r-0.49$, $P=0.03)$. The physical activity level was not related to the body composition (results not shown) of the patients and was not different between month 1 and 3 .

\section{Discussion}

The results show no clear changes in body mass for both groups. At 1 month after discharge, small differences in energy balance between the intervention and control group became visible. The positive energy balance in the intervention group resulted in a weight gain from month 1 to month 3 . However, after 3 months the intervention group did not have a higher body-mass increase than the control group. Probably, the intervention group compensated for the nutritional supplements by reducing their other food intake. During the recording week the intervention group consumed on average $95 \pm$ SD $6 \%$ of the prescribed nutritional supplements at month 1 and 89 $\pm \mathrm{SD} 14 \%$ of the prescribed nutritional supplements at month 3. Not all prescribed supplements were consumed, which might also be a reason for the low weight increase 
in the intervention group. Furthermore it might be that the sample size was not sufficient to find an effect of supplementation on energy balance. The power of the current study was calculated to elucidate the influence of physical activity on energy balance, as this was the main focus of the present study.

The physical activity level of about 1.56 in this group of outpatients with COPD was lower than measured in COPD patients in a rehabilitation centre (Baarends et al. 1997) and lower than measured in a group of healthy elderly men and women (Meijer et al. 2001). In the rehabilitation centre patients followed a daily programme including physical exercises, which might be the reason for the higher physical activity level. Additionally, the physical activity level of the COPD patients in the rehabilitation centre was calculated from EE measured with the doubly labelled water method and BMR measured with the ventilated hood. Thus, the activity-related EE included also energy needed for the decreased mechanical efficiency in COPD patients (Baarends et al. 1997). Here, physical activity was estimated with a tri-axial accelerometer for movement registration and an eventually lower mechanical efficiency was not taken into account.

At home, physical exercise is probably limited in COPD patients. However, a temporarily lower physical activity level is not negative per se in weight-losing or depleted COPD patients. COPD patients with a lower physical activity level were able to eat sufficient for their energy needs and remained in energy balance or even gained weight (Fig. 1). A high physical activity level must be accompanied with a higher energy intake to maintain at least energy balance. This was probably difficult for the depleted COPD patients with a high physical activity level, because they lost weight. In a controlled setting, a rehabilitation centre, patients with a high physical activity level were still able to maintain their body weight or even gained weight (Creutzberg, 2003). More research is needed, to target physical activity and food intake to depleted outpatients with COPD. Our results indicate that some of the depleted patients might even temporarily require enteral tube feeding.

The food intake was reported accurately and the patients did not change their diet while food recording. The patients were motivated to report their food intake accurately and had probably sufficient time to record everything, because they were mostly at home. Results on reported food intake could therefore be used to compare the energy balance between the intervention and control group.

The water-balance technique can give an indication of whether subjects recorded their food intake accurately. A good recording of water intake does not necessarily imply that the same holds for the recording of food intake. Most foodstuffs contain a certain amount of water and therefore if an individual records his/her water intake accurately it is expected that they record their whole food intake accurately. Also a good recording does not say anything about a change in diet while food recording and body-mass changes over the recording period must be measured. Earlier studies showed that the water-balance method was able to measure misrecording of food intake on the group level. The sum of a change in diet 
Table 3. Total water intake (recorded+metabolic water), water loss and body-mass changes over the recording week and a non-recording week for the total group at 1 and 3 months after dischargeł

(Mean values and standard deviations)

\begin{tabular}{|c|c|c|c|c|c|c|c|c|}
\hline & \multicolumn{2}{|c|}{ Water intake $(\mathrm{l} / \mathrm{d})$} & \multicolumn{2}{|c|}{ Water loss $(1 / d)$} & \multicolumn{2}{|c|}{$\begin{array}{l}\text { Body-mass change } \\
\text { over recording } \\
\text { week }(\mathrm{kg})\end{array}$} & \multicolumn{2}{|c|}{$\begin{array}{l}\text { Body-mass change } \\
\text { over non-recording } \\
\text { week }(\mathrm{kg})\end{array}$} \\
\hline & Mean & $\mathrm{SD}$ & Mean & $\mathrm{SD}$ & Mean & SD & Mean & SD \\
\hline Month 1 ( $n$ 20) & $2 \cdot 7$ & 0.7 & $2 \cdot 8^{*}$ & 0.7 & 0.08 & 0.51 & $0.09 \dagger$ & 0.51 \\
\hline Month 3 (n 19) & 2.5 & 0.7 & $2 \cdot 6^{*}$ & 0.7 & 0.09 & 0.68 & $-0.16 t$ & 0.73 \\
\hline
\end{tabular}

* Water loss was insignificantly different from water intake ( $P=0.03$ and $P=0.1$ for month 1 and 3 respectively) (paired $t$ test).

†Body-mass change during the recording week was insignificantly different from that during the non-recording week $(P=0.95$ and $P=0.4$ for month 1 and 3 respectively) (paired $t$ test).

‡For details of subjects, and procedures see Table 1 and p. 726, 727.

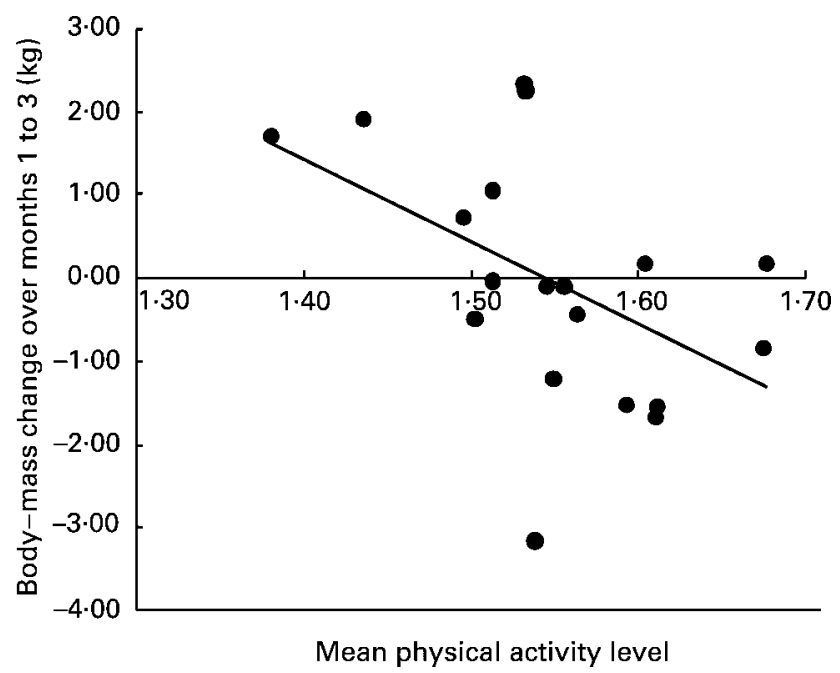

Fig. 1. Body-mass change from month 1 to month 3 plotted against the mean physical activity level ( $n 19 ; r-0.49 ; P=0.03)$.

and misrecording as assessed with the water-balance method was equal to the total amount of misreporting as measured with the doubly labelled water method (Goris et al. 1999, 2001). A good reporting of food intake in free-living subjects is not very common, as most subjects tend to misrecord their food intake or change their diet while food recording (Goris et al. 1999).

In summary, the weight change from month 1 to month 3 was negatively associated with the energy requirement for physical activity. These preliminary results suggest that knowledge about the individual physical activity level is necessary for the estimation of the energy need of the patient and to give appropriate advice about food intake and the use of supplements. However, more research is needed to find out which combination of oral or enteral supplementation and physical activity results in the highest weight gain and functional improvement in depleted COPD patients at home.

\section{References}

Baarends E, Schols A, Pannemans D, Westerterp K \& Wouters E (1997) Total free living energy expenditure in severe chronic obstructive pulmonary disease. American Journal of Respiratory Critical Care Medicine 155, 549-554.
Creutzberg EC, Wouters EFM, Mostert R, Weling-Scheepers CAPM \& Schols AMWJ (2003) Efficacy of nutritional supplementation therapy in depleted patients with chronic obstructive pulmonary disease. Nutrition (In the Press).

Efthimou J, Fleming J, Gomes C \& Spiro SG (1988) The effect of supplementary oral nutrition in poorly nourished patients with chronic obstructive pulmonary disease. American Review of Respiratory Diseases 137, 1075-1082.

Fjeld CR, Brown KH \& Schoeller DA (1988) Validation of the deuterium oxide method for measuring average daily milk intake in infants. American Journal of Clinical Nutrition 48, 671-679.

Goris AHC, Meijer EP, Kester A \& Westerterp KR (2001) The use of a tri-axial accelerometer for the validity of reported food intake. American Journal of Clinical Nutrition 73, 549-553.

Goris AHC \& Westerterp KR (1997) Underreporting of habitual food explained by undereating in motivated lean women. Journal of Nutrition 129, 878-882.

Lewis MI, Belman MJ \& Dorr-Uyemura L (1987) Nutritional supplementation in ambulatory patients with chronic obstructive pulmonary disease. American Review of Respiratory Diseases 135, 1062-1068.

Meijer EP, Goris AHC, Wouters L \& Westerterp KR (2001) Physical inactivity as a determinant of the physical activity level in the elderly. International Journal of Obesity 25, 935-939.

Mostert R, Goris A, Weling-Scheepers C, Wouters EFM \& Schols AMWJ (2000) Tissue depletion and health related quality of life in patients with chronic obstructive pulmonary disease. Respiratory Medicine 9, 859-867.

Schols AMWJ, Slangen J, Volovics L \& Wouters EFM (1998) Weight loss is a reversible factor in the prognosis of chronic obstructive pulmonary disease. American Journal of Respiratory Critical Care Medicine 157, 1791-1797.

Schols AMWJ, Soeters PB, Mostert R, Pluymers RJ \& Wouters EFM (1995) Physiologic effects of nutritional support and anabolic steroids in patients with chronic obstructive pulmonary disease. American Journal of Respiratory Critical Care Medicine 152, 1268-1274.

Schols AMWJ, Soeters PB, Mostert R, Saris WHM \& Wouters EFM (1991) Energy balance in chronic obstructive pulmonary disease. American Review of Respiratory Diseases 143, $1248-1252$.

Westerterp KR, Kayser B, Brouns F, Herry JP \& Saris WH (1992) Energy expenditure climbing Mt. Everest. Journal of Applied Physiology 73, 1815-1819.

Wilson DO, Rogers RM, Wright EC \& Anthonisen NR (1989) Body weight in chronic obstructive pulmonary disease. American Review of Respiratory Diseases 139, 1435-1438. 